\title{
Prior Treatment of Current Cancer
}

National Cancer Institute

\section{Source}

National Cancer Institute. Prior Treatment of Current Cancer. NCI Thesaurus. Code C156800.

An indication that an individual has previously received therapy for their current malignancy. 